\title{
La integración de las mujeres del Magreb en Euskadi: algunas reflexiones para la intervención social
}

\section{Maitane Mardaras Pérez}

Universidad de Deusto

Trinidad L. Vicente Torrado

Universidad de Deusto

<trinidad.vicente@deusto.es>
Gure gizartean, Magrebtar emakumeen presentzia integrazioari eta integrazio soziala lortzeko eskuartze sozialaren arlotik kontuan hartu beharreko neurriei dagokionez, eztabaida anitz sortzen ari da. Nahiz eta etorkinak gizarte hartzailean integratzeko maila teorikoan modelo eta dimentsio desberdinak aitortzen diren, desberdintasun kulturalak kontutan hartzeaz gain, normalean eztabaida kontzeptu sinpleagoetan planteatzen da. Horregatik, artikulu honek, lehenik eta behin integrazio-eredu desberdinen gogoeta bat egiten du, gure gizarteak egin duen hautaketara eramanez: integrazio interkulturala. Gero, integrazioaren dimentsio nagusiak nabarmentzen dira, eta azkenik, dimentsio bakoitzeko aldagai batzuk kontuan hartuz emakume magrebtarren errealitatea euskal gizartean aztertzen da. Eta hura guztia, lortu nahi den integrazio interkulturala kalibratze asmoarekin, eta eskuartze sozialean onuragarri izango liratekeen neurri posibleak azalerazte asmoarekin.

\section{GAKO-HITZAK:}

Immigrazioa, emakumeak, Magreb, integrazio soziala, integrazio kulturala.
La presencia de mujeres magrebíes en nuestra sociedad está abriendo numerosos debates en torno a su integración. Aunque en el plano teórico se reconocen distintos modelos de incorporación de la población inmigrante a la sociedad receptora y sus dimensiones más allá de las diferencias culturales, en la práctica el debate se plantea frecuentemente en términos mucho más reducidos. Por ello, este artículo aborda, en primer lugar, una reflexión en torno a los distintos modelos de integración, señalando la elección llevada a cabo por nuestra sociedad: la integración intercultural. Posteriormente, se destacan las principales dimensiones de la integración y, por último, se analiza la realidad de las mujeres magrebíes en la sociedad vasca de acuerdo a algunas variables correspondientes a cada una de esas dimensiones. Todo ello tiene el objeto de evaluar el logro de la pretendida integración intercultural, así como de esclarecer las posibles medidas de intervención social que pudieran favorecerla.

\section{Palabras Clave:}

Inmigración, mujeres, Magreb, integración social, integración cultural. 


\section{Introducción}

La población de origen magrebí es uno de los colectivos inmigrantes que menos aceptación genera en la sociedad vasca, una reprobación que viene creada, en gran parte, por el desconocimiento que ha existido y que aún persiste sobre el mundo musulmán. La escasa -y segmentada- información que se nos transmite en los países occidentales en torno a la inmigración internacional, al islam y a los países del Magreb está favoreciendo, en muchas ocasiones, una imagen negativa de las personas procedentes del norte de África, cada vez más presentes en nuestro entorno social.

Hasta hace relativamente poco tiempo, los estudios realizados sobre los flujos migratorios hacían referencia a la realidad de los hombres, ofreciendo en muchas ocasiones una visión androcéntrica de este fenómeno social y omitiendo la inmigración femenina. Esta invisibilización de las migraciones protagonizadas por mujeres era fruto de la presunción de que, cuando las mujeres deciden migrar, lo hacen siguiendo a sus esposos o padres, lo cual las convierte en personas dependientes que apenas influyen en esa decisión y, por tanto, resultan irrelevantes para entender por qué se producen esos movimientos poblacionales. Y cuando raramente se reconocía que las mujeres emigraban por sí mismas, las causas de partida y sus comportamientos migratorios se consideraban semejantes a los de los hombres, por lo que frecuentemente tampoco se estimaba necesario profundizar en el asunto.

No obstante, a partir de los años noventa se va a poner de manifiesto la especificidad de la migración femenina, con el creciente desarrollo de corrientes migratorias de carácter laboral a escala mundial, como respuesta al aumento de la demanda de trabajadoras migrantes principalmente en tres sectores económicos de los países más desarrollados: la industria del sexo, el sector de los cuidados personales y el servicio doméstico. Se va a iniciar así un prolijo campo de investigación interdisciplinar que va a poner de manifiesto los proyectos autónomos protagonizados por muchas mujeres migrantes, entre las que podemos ubicar también a algunas inmigrantes provenientes del Magreb.

Por otra parte, en las sociedades occidentales existe la idea generalizada de que las personas procedentes de los países del Magreb presentan muchos problemas de integración, porque no desean -o no pueden- integrarse en el país de acogida, al tiempo que tratan de imponer sus propias costumbres en él. Esta situación parece afectar de forma especialmente negativas a las mujeres, quienes, discriminadas por su propia cultura y aisladas precisamente por ella de la sociedad receptora, constituyen uno de los colectivos con más bajos niveles de integración social en la actualidad. Este artículo trata precisamente de abordar esta cuestión, con el objetivo de conocer qué dimensiones y variables socioculturales, tanto desde la perspectiva de la comunidad de origen como de la de acogida, influyen en la integración de las mujeres del Magreb residentes en Euskadi.

El artículo se estructura en tres apartados principales. En el primero, nos centraremos en el debate en torno a los modelos de integración, haciendo especial hincapié en el modelo elegido por la sociedad vasca: el intercultural; en el segundo, describiremos las principales dimensiones de la integración social; y en el tercero, trataremos de analizar la integración social de las mujeres del Magreb residentes en el País Vasco, seleccionando para ello algunas variables de cada una de las dimensiones señaladas. Para ello nos valdremos de distintos estudios teóricos, así como de fuentes secundarias que, empleando distintas metodologías de investigación (cuantitativas y cualitativas), nos aportan información relevante para analizar la realidad de las mujeres de origen magrebí que ya forman parte de la sociedad vasca.

\section{El debate en torno a los modelos de integración}

La creciente presencia de personas inmigrantes en nuestra sociedad, procedentes a su vez de una cada vez mayor diversidad de lugares, está abriendo un amplio debate en torno al modo en el que se han de incorporar -y de hecho se están incorporando- a nuestra sociedad. Mucho se habla sobre la importancia de la integración social de las personas inmigrantes, pero no parece existir consenso a la hora de definir en qué consiste precisamente esa inclusión, de la que ya forman parte. La integración suele ser percibida como un objetivo necesario y generalmente parece venir acompañada de una cierta connotación positiva, de un amplio grado de deseabilidad; pero al mismo tiempo se presenta como un concepto complejo y confuso, que engloba distintos significados.

No es nuestro objetivo en este artículo presentar todos los modelos posibles de integración o incorporación de la población inmigrante a una nueva sociedad $^{1}$, pero sí queremos destacar las características principales, aunque sea de forma muy resumida, de los tres modelos teóricos probablemente más mencionados en el debate público en torno a este tema: el asimilacionismo, el multiculturalismo y el interculturalismo.

\subsection{El asimilacionismo}

La asimilación, probablemente el modelo más rechazado en el plano teórico, pero muy presente en las prácticas cotidianas, defiende la adhesión unilateral de la población inmigrante a la sociedad de acogida ("allá donde fueres, haz lo que vieres", reza el refra-

${ }^{1}$ Para profundizar en este aspecto, existe una amplia bibliografía, entre la que podemos citar Malgesini y Giménez (1997); Blanco Fdez. Valderrama (1993, 2001 y 2002); Checa, Arjona y Checa (2003); Giménez Romero (2003); De Lucas y Torres (2002); Maalouf (2001); Santamaría (2002); o Pumares (1998). 
nero español). El objetivo de este modelo de integración, cuyo origen se sitúa a comienzos del siglo XX, es lograr una sociedad homogénea. Como señalan Malgesini y Giménez (1997: 51), “el asimilacionismo constituye una propuesta de uniformación cultural: se propone y se supone que los grupos y las minorías van a ir adoptando la lengua, los valores, las normas y las señas de identidad de la cultura dominante y, en paralelo, van a ir abandonando su propia cultura". Y, en cambio, deja de lado el criterio social (Vidal Fernández y Martínez Martínez, 2006: 97). Concebida como un proceso lineal global, la asimilación ha constituido, hasta fechas recientes, el paradigma dominante del modo de adaptación de la población inmigrante a una nueva sociedad, ya que se entendía que producía la igualación social y la eliminación de toda discriminación y prejuicio por parte de la sociedad receptora, siendo éste el resultado natural e inevitable del contacto interétnico o intercultural (Blanco Fdez. de Valderrama, 1993: 165-166).

Ahora bien, este modelo ha recibido fuertes críticas por distintas razones. En primer lugar, parte de que las sociedades receptoras son homogéneas internamente, cuando de hecho no lo son. No tenemos más que pensar en la propia sociedad vasca para descubrir que es precisamente la heterogeneidad, la diversidad, lo que la caracteriza (tanto desde el punto de vista social como político, religioso, lingüístico). Podríamos entonces preguntarnos hacia dónde se tiene que dirigir dicha asimilación; más aún, si dicha homogeneización o propuesta de uniformación cultural como meta es posible e, incluso, si es deseable. Este modelo de integración, que parece responder principalmente a un ejercicio de poder, presenta, además, una visión estática de la cultura y, como señala Márquez (cit. en Pumares, 1998: 296), deja toda la responsabilidad de la integración en manos de la población inmigrante, por lo que la propia exigencia de la asimilación sirve de excusa para la exclusión y la discriminación: en tanto que la población inmigrante no se asimila perfectamente (lo que, en la realidad, no es factible), la culpa de su marginación recae sobre ella, precisamente por no 'integrarse'.

Ante esta situación, en la actualidad pocas son las personas defensoras de la asimilación en el ámbito científico, si bien es todavía un planteamiento ampliamente compartido por las poblaciones receptoras ante la llegada de personas procedentes de otros ámbitos socioculturales, aunque reciba otras denominaciones.

\subsection{El multiculturalismo}

El multiculturalismo, al igual que el interculturalismo, parte del reconocimiento del pluralismo cultural y del rechazo a la asimilación (de hecho, en el debate público frecuentemente se utilizan de forma indistinta los términos pluralismo cultural, multiculturalismo e interculturalismo para referirse al mismo modelo de integración, aunque presentan ciertas diferencias dignas de consideración). El multicul- turalismo es un modelo de integración dentro del paradigma pluralista, que surge durante los años sesenta y setenta, tomando como principios básicos "el respeto y asunción de todas las culturas, el derecho a la diferencia y la organización de la sociedad de tal forma que exista igualdad de oportunidades y de trato y posibilidades reales de participación en la vida pública y social para todas las personas y grupos, con independencia de su identidad cultural, etnoracial, religiosa o lingüística" (Malgesini y Giménez, 1997: 291-292). El principio básico del multiculturalismo es, por tanto, el derecho a la diferencia. En la medida en que se respeten las distintas culturas de los diferentes grupos presentes en una sociedad, sus miembros se sentirán más seguros y, por tanto, serán más capaces de aceptar a los demás y de establecer unas relaciones interétnicas positivas (Blanco Fdez. de Valderrama, 1993: 144).

Además de reivindicar el derecho a la tolerancia de los diferentes, el multiculturalismo reivindica el derecho de los grupos a tener un lugar institucionalmente reconocido en el ámbito político y a recibir apoyos públicos para no disgregarse. Por todo ello, la literatura sociológica desde esta visión se va a referir fundamentalmente a la organización de estas minorías y a las relaciones interétnicas entre ellas. Según este modelo, si una persona inmigrante no puede asociarse públicamente con personas de su misma nacionalidad, tendrá mayores dificultades para defender públicamente sus derechos (Vidal Fernández y Martínez Martínez, 2006: 98). Bajo el paraguas del término 'tolerancia', se incentiva a la ciudadanía a vivir en su comunidad y tolerar a las otras comunidades etnoculturales que se encuentran en una sociedad determinada (Taylor, 2001: 59).

Este modelo, no obstante, también ha recibido importantes críticas, ya que parece impulsar únicamente las relaciones intracomunitarias, fomentando el mantenimiento de fuertes símbolos identitarios, al tiempo que plantea la mera coexistencia de estos diversos grupos presentes en una misma sociedad, sin potenciar la convivencia y el intercambio entre ellos, lo que podría derivar en una cierta fragmentación social (Retortillo et al., 2008: 127). En este sentido, John Rex señaló, ya en la década de los ochenta, que el multiculturalismo presenta dificultades claras, puesto que defiende la existencia de dos ámbitos culturales independientes: "el de una cultura política compartida dentro del dominio público, basada en la idea de la igualdad" de las personas y, por otro lado, "el de un número de diversas culturas comunitarias y privadas, cada una con su lengua, con su religión, prácticas familiares y otras costumbres". Pero "lo que ocurre en el ámbito de lo público está muy influenciado por los procesos de socialización y apoyo procedentes de la esfera comunitaria y privada; y algunas instituciones, y en especial el sistema escolar, van a horcajadas de ambas" (cit. en Malgesini y Giménez, 1997: 296).

Desde el multiculturalismo podría justificarse, por tanto, un trato desigual a determinadas personas. 
Este modelo, a su vez, partiendo de una noción estática y esencialista de la cultura, parece sobredimensionar las diferencias culturales, olvidando que probablemente ni todas las personas que conforman un grupo determinado -el inmigrante, por ejemplo-, ni en toda circunstancia, prefieren permanecer separadas del resto de grupos presentes en esa sociedad -o del colectivo mayoritario que compone la sociedad receptora, por ejemplo-, sino que muchas de estas personas lo que querrán será entrar a formar parte de esa nueva sociedad, eso sí, como ciudadanos y ciudadanas de pleno derecho. Tal y como destaca Kymlicka (1996: 25), quienes se oponen al multiculturalismo defienden que es éste un modelo que coloca a los grupos minoritarios en guetos, impidiéndoles su integración en el conjunto de la sociedad, mientras que quienes se muestran partidarios de este modelo señalan que la preocupación por la integración es una simple muestra del imperialismo cultural reinante en nuestras sociedades.

\subsection{El interculturalismo}

Ante las críticas recibidas por el modelo multicultural, desde épocas recientes se viene acuñando un nuevo término, interculturalismo, para definir un nuevo modelo de integración social. Este concepto, al igual que el multiculturalismo, parte del pluralismo cultural, es decir, que defiende que es posible que en una misma sociedad convivan de forma armónica distintos grupos étnicos, culturales, religiosos o lingüísticos, siendo esa diversidad juzgada positivamente. Pero a diferencia del multiculturalismo, defiende una perspectiva más dinámica de la cultura y de la creación de identidades, sujetas a cambios provocados por las tensiones internas (momento crítico intracultural) y por los contactos con otras culturas (momento crítico intercultural). De la interacción entre distintos grupos sociales, no siempre exenta de conflicto, puede resultar un nuevo modelo de sociedad, del que las diversas personas que la componen se sientan parte.

Pero asumir la creación de una sociedad intercultural requiere el replanteamiento de una serie de ideas en torno a la integración. En este sentido, podemos comenzar destacando que el interculturalismo exige reconocer que en el proceso de integración no sólo han de jugar un papel fundamental los grupos minoritarios, sino que la sociedad mayoritaria tiene también una responsabilidad fundamental en aquél. Así, en el caso de la inmigración, por ejemplo, el interculturalismo plantea tomar como base el valor del respeto a la diferencia, así como la necesidad de establecer lo que, en palabras de Pumares, podría denominarse "un acuerdo de mínimos, sobre el que asentar una reglas básicas de convivencia” (1998: 297).

En este proceso, la población inmigrante habrá de hacer los mayores esfuerzos, como señala este autor, y en buena medida de forma obligada, ya que al encontrarse en un entorno diferente al de su país de origen va a verse forzada inevitablemente a introdu- cir cambios, a aprender las normas fundamentales de comportamiento vigentes, a aprender el idioma, y al mismo tiempo se va a ver influida por el nuevo sistema de valores predominante en la sociedad de destino, aunque ello no debe implicar necesariamente la entrada en un proceso de asimilación. Pero la sociedad receptora, de igual manera, va a tener que introducir cambios para adaptarse a esta nueva situación y para que este proceso de integración se realice con éxito; cambios que no sólo hacen referencia a la dimensión cultural (respeto y apertura hacia otras culturas, valores y costumbres), sino que también implican la necesidad de remover todos los obstáculos que impidan que estas personas puedan disfrutar de los mismos derechos -y no sólo de los mismos deberes- en nuestra sociedad (Cebrián y Moreno, 2008: 10). Esto va a significar la consideración de otras dimensiones, como la legal o la socioeconómica, que permitan la igualdad de oportunidades en el acceso al trabajo, a la vivienda, a la salud, a la educación, a los servicios sociales, a la participación política: en definitiva, a cualquier ámbito de la vida social. Desde este modelo, por tanto, la integración no es entendida únicamente como un proceso de adaptación cultural, sino que se trata de un concepto multidimensional (Pumares, 1998: 299-301; Vidal Fernández y Martínez Martínez, 2006: 86).

La cultura, entendida como el "conjunto trabado de maneras de pensar, de sentir y de obrar más o menos formalizadas que, aprendidas y compartidas por una pluralidad de personas, sirve de un modo objetivo y simbólico a la vez para constituir a esas personas en una colectividad particular y distinta" (Rocher, 1985: 111-112), no es un fin en sí misma para el modelo interculturalista, que de esta forma trata de superar el multiculturalismo. Según este nuevo modelo, además, el hecho de que la población inmigrante no pierda ni sea obligada a cambiar su cultura de origen no significa que no se vayan a introducir modificaciones en ésta. En cualquier caso, la cultura es parte fundamental de la identidad de las personas y tiene una función adaptativa y, por tanto, cambiante; aunque los cambios que se introduzcan deber ser progresivos, asumidos y decididos por ella (Pumares, 1998: 302).

En este sentido, muchos autores defienden que el interculturalismo podría resultar, en una fase previa, a la asimilación, especialmente en el caso de las segundas y sucesivas generaciones, ya que éstas irían perdiendo los rasgos característicos de la cultura minoritaria y adoptando aquellos de la cultura mayoritaria. No obstante, también es preciso tener en cuenta que el proceso de integración intercultural tampoco ha de ser concebido como lineal, global y único, ya que una misma persona puede sentirse integrada en determinados ámbitos de su vida social, pero no en todos, con lo que no resultaría ni plenamente integrada ni absolutamente inadaptada, y podría, incluso, vivir situaciones distintas que encajaran en los diferentes modelos. Además, el cambio no tiene por qué ser unidireccional, sino que a lo largo del tiempo puede evolucionar de diferentes 
maneras, por lo que en ningún momento hemos de bajar la guardia y dar por concluido el esfuerzo de integración de las distintas personas y de los grupos de los que forman parte y que conforman una determinada sociedad en un momento concreto.

Ahora bien, el modelo intercultural, surgido recientemente ante las críticas dirigidas hacia el multiculturalismo, está todavía poco sistematizado. Más que una realidad social, refleja un ideal que todavía resulta difícil de plasmar en la práctica. Este modelo, que plantea concentrar la atención en aquellas claves que faciliten la comprensión y la gestión de la diversidad, evitando recalcar las diferencias, ha de tener en cuenta que los diversos grupos socioculturales ocupan distintas posiciones en la estructura social; $y$, por otra parte, que los procesos que propone abordar se desarrollan asimismo en planos de desigualdad o asimetría (Vidal Fernández y Martínez Martínez, 2006: 100).

De lo destacado hasta aquí se desprende, no obstante, que la elección de un modelo de integración social u otro no resulta con todo banal, ya que en cierta medida refleja el proyecto de sociedad al que se aspira. En este sentido, defendemos que la apuesta por una sociedad intercultural, aun no estando exenta de importantes dificultades e imprecisiones, parece la más oportuna. Estamos, sin duda, ante un reto difícil, pero que tenemos que afrontar, dadas las implicaciones que conlleva.

\section{Dimensiones de la integración social}

A menudo la mera inserción en el tejido productivo del país de acogida, cuando no las diferencias culturales, son utilizadas para argumentar si una persona se encuentra o no integrada socialmente; aunque, como se ha destacado en el apartado anterior, la integración conforma un proceso multidimensional, dinámico y bidireccional de adaptación mutua entre todas las personas e instituciones de una determinada sociedad. Por ello, cuando se habla de integración surge la ineludible necesidad de distinguir conceptualmente entre sus distintas dimensiones.

En este artículo, y siguiendo la propuesta de Vidal Fernández y Martínez Martínez (2006: 86), el concepto de integración va quedar estructurado en torno a cuatro dimensiones:

- La dimensión estructural se refiere a los aspectos normativos de la integración. Según el principio de igualdad de oportunidades, esta dimensión engloba las condiciones que determinan la participación de las personas en las instituciones de las sociedades avanzadas. Entre las variables que incluye esta dimensión, encontramos las siguientes: situación administrativa, estatus dentro de los sistemas de educación y cualificación, posición en el mercado laboral, fuentes de recursos económicos, acceso a la vivienda y acceso a los sistemas de bienestar.
- La dimensión cognitivo-cultural hace referencia al proceso que engloba el aprendizaje de habilidades cognitivas y el manejo de la cultura del país de acogida. Las variables que lo determinan son: el conocimiento del idioma y de la cultura del país, los valores políticos, los valores culturales, las creencias religiosas y los estilos de vida.

- La dimensión social se refiere a las relaciones sociales y grupales de las personas, al desarrollo de éstas dentro o fuera de su comunidad étnica, y a la facilitación de cauces de participación en la sociedad receptora de los colectivos inmigrantes. Factores determinantes para la definición de esta dimensión serían: la extensión e identidad de las relaciones familiares, el contacto con los miembros de la misma comunidad; los contactos con el vecindario, las relaciones de amistad o noviazgo, y la pertenencia o vinculación a asociaciones voluntarias (ONG).

- La dimensión de identidad abarca los aspectos subjetivos de pertenencia e identificación personal con la comunidad étnica o nacional. Es necesario mencionar que existen diversos matices intermedios entre la identificación absoluta y la desidentificación total con la cultura de origen o de destino. Las variables que incluye esta dimensión son: la percepción subjetiva de pertenencia, las actitudes de la población inmigrante hacia la sociedad de acogida y de ésta hacia aquélla, la clase y el grado de identificación con ella, y la orientación de la sociedad de acogida hacia las relaciones interculturales.

En todo caso, es preciso recalcar que las distintas dimensiones de la integración están interrelacionadas, por lo que los resultados obtenidos en un ámbito refuerzan, al mismo tiempo, los obtenidos en los otros (Niessen y Schibel, 2004: 11).

\section{La integración social de las mujeres del Magreb en Euskadi}

A continuación, y con objeto de evaluar el nivel de integración social de las mujeres del Magreb residentes en Euskadi, vamos a tomar algunas de las variables correspondientes a cada una de las cuatro dimensiones planteadas y a analizarlas a partir de fuentes secundarias que se irán detallando en cada apartado concreto.

En la dimensión estructural, las variables que consideraremos serán la situación administrativa y la laboral, que están estrechamente relacionadas. En la dimensión cognitivo-cultural, las variables que se tendrán en cuenta serán el conocimiento de los idiomas de la sociedad de acogida, y el aprendizaje y afianzamiento del idioma materno. En la dimensión social, las variables que se analizarán serán los contactos con los miembros de la misma comunidad y con el vecindario, incluyendo algunos controvertidos temas, como el uso del velo islámico en el espacio público o la función de las mezquitas en la 
integración de las mujeres magrebíes en la sociedad vasca. Y, por último, en la dimensión de identidad, las variables que se considerarán serán la percepción subjetiva de pertenencia y la actitud de la población del país de acogida hacia estas mujeres inmigrantes procedentes del Magreb.

\subsection{Dimensión estructural}

Frecuentemente cuando se habla de integración de la población inmigrante se sobredimensionan las diferencias debidas a la cultura y no se tiene suficientemente en cuenta, en cambio, el lugar que la persona inmigrante ocupa en la estructura social. Variables como la situación administrativa o la incorporación laboral en la sociedad de acogida, muy interrelacionadas entre sí, resultan centrales a la hora de evaluar la integración de las mujeres del Magreb en nuestra sociedad, y por ello nos vamos a centrar en ellas dentro de este apartado dedicado a la dimensión estructural.

La consecución o mantenimiento de los documentos legales para trabajar o residir en nuestra sociedad son, sin duda, una de las preocupaciones fundamentales de las personas inmigrantes, y no únicamente de quienes se encuentran en situación irregular. Los permisos de trabajo y residencia dan la seguridad de permanecer en el país y permiten el disfrute de distintos derechos, a la vez que posibilitan o facilitan muchas gestiones y actividades diarias, que se convierten en muy complicadas para las personas indocumentadas. Ya desde el inicio del proyecto migratorio, a la hora de cruzar la frontera, hay quienes lo hacen de manera regular, con la necesaria documentación, y quienes lo hacen de forma indocumentada. Pero aun quienes llegan con un permiso de residencia -en la mayor parte de los casos, temporal-, se pueden encontrar en situación irregular al cabo de cierto tiempo, ya que conservar la residencia legal no resulta nada fácil.

Las mujeres del Magreb residentes en Euskadi conforman un grupo de 8.340 personas, y representan el $35 \%$ de las personas inmigrantes de esta procedencia geográfica y casi el $9 \%$ del total de mujeres inmigrantes en la sociedad vasca (INE, 2014). La mayor parte de las mujeres mayores de 16 años de origen extranjero llevan más de seis años viviendo en Euskadi (58\%), y esta tendencia también muestran las mujeres magrebíes, si bien con una intensidad algo inferior (53\%) [Gobierno Vasco, 2011]. Casi ocho de cada diez inmigrantes llegadas desde el norte de África afirman no haber estado nunca en situación irregular (frente al $40 \%$ de sus compatriotas masculinos). Ello no resulta sorprendente si tenemos en cuenta que la reagrupación familiar es la principal vía de entrada de las mujeres del Magreb, siendo mucho menos frecuente la entrada como turista o con un contrato laboral. Y aunque motivo migratorio y vía de entrada no siempre coinciden, en el caso de la inmigración femenina de esta procedencia sí se da cierta correspondencia entre ambas variables: prácticamente la mitad de las mujeres magrebíes residentes en Euskadi dicen haber venido para acompañar a sus familias ( $48 \%$ ), siendo menor, en cambio, el grupo que señala como proyecto migratorio el inicio de una nueva vida (36\%), o la consecución de dinero o un proyecto educativo (16\%) (Martín, Moreno y Fullaondo, 2012).

Quizá por todo ello, no sorprende que la tasa de actividad de las mujeres magrebíes con edades comprendidas entre los 16 y los 66 años (38\%) sea claramente inferior a la registrada por la inmigración femenina residente en el País Vasco (69\%). Ahora bien, este colectivo femenino procedente del norte de África también conforma uno de los grupos que más dificultades enfrenta a la hora de encontrar un empleo, tal y como indica su tasa de desempleo ( $49 \%$ frente al $26 \%$ de la inmigración femenina en su conjunto considerada). Más aún, su incorporación laboral se realiza frecuentemente en los nichos de empleo de menor cualificación, como el servicio doméstico (7\%), la hostelería (37\%) o el comercio al por menor (28\%) [lkuspegi@kObservatorio Vasco de Inmigración, 2012]: unas escasas y precarias opciones laborales que son claramente percibidas por este colectivo (Fuentes Nogales y Vicente Torrado, 2007: 66).

En definitiva, si bien en cuanto a la situación administrativa la integración de las mujeres inmigrantes pudiera calificarse de positiva, tal dictamen se pone en entredicho si consideramos su incorporación al mercado laboral. Y es que esta última, si por algo se caracteriza, es por su precariedad, lo que condiciona la adquisición de los necesarios recursos económicos, así como el cumplimiento del requisito de empleo para conseguir un permiso de trabajo de forma independiente, o la reagrupación familiar. La mayoría de las mujeres magrebíes afirman que su proyecto migratorio es de carácter familiar, pero también es preciso reconocer que el desarrollo de un proyecto migratorio individual constituye, para estas mujeres, todo un reto al que tienen que hacer frente con sus limitaciones (administrativas, lingüísticas) y con las que les impone el resto de la sociedad (cuando las rechaza por una percibida mayor distancia sociocultural, por ejemplo).

\subsection{Dimensión cognitivo-cultural}

A través de los símbolos, las personas transmiten sus conocimientos, sus normas, sus costumbres, sus valores. Y de todos los sistemas simbólicos, el más importante es el lenguaje, ya que sólo sirve para la creación de cultura. A través de la lengua, todos los grupos culturales mantienen sus rasgos culturales, siendo a través de ésta como se representan las características étnicas, culturales y nacionales, y al mismo tiempo se construyen las categorías de pensamiento de las personas.

En la actualidad, el bilingüismo o el multilingüismo están presentes en prácticamente todos los países del mundo (Jiménez Gámez, 2012: 146). El lenguaje tiene un aspecto ideológico importante, ya se rela- 
ciona con las políticas lingüísticas que se implementan en el lugar de asentamiento y que, por tanto, condicionan el sentimiento identitario de las personas inmigrantes (Relaño y Soriano, 2006: 88).

En las investigaciones realizadas a escala del Estado español, apenas se ha introducido hasta el momento el conocimiento del idioma como facilitador u obstructor de la integración en la sociedad de acogida (Relaño y Soriano, 2006: 90). En todo caso, a escala internacional sí existe un consenso en torno a la importancia de la adquisición de la lengua de la sociedad de recepción como herramienta imprescindible para la plena integración de las personas inmigrantes, de modo que el insuficiente conocimiento del idioma obstaculiza, por el contrario, la integración (Villarreal, 2009). El nivel de conocimiento del idioma, en definitiva, está estrechamente ligado al grado de inclusión y exclusión de las personas en la sociedad.

Una comunicación de la Comisión Europea de 2003 ya señalaba que una preocupación básica en la mayoría de los Estados miembros es que la población inmigrante esté capacitada para hablar la lengua o lenguas del país de acogida. Se considera que un conocimiento insuficiente del idioma es el principal obstáculo a una buena integración. Una idea compartida por el Consejo Europeo, que un año más tarde, en noviembre de 2004, acordó los principios básicos comunes para una política de integración de la población inmigrante en la Unión Europea, señalando en el cuarto de ellos que, para que la integración tenga éxito, es esencial permitir a la población inmigrante la adquisición de esos conocimientos de idioma, de historia y de las instituciones de la sociedad de acogida. Y, ahondando en esta misma línea, en septiembre de 2005, la Comisión Europea presentó un Programa Común para la Integración, en el cual se abogaba por la organización de programas, cursos y actividades de acogida para las personas inmigrantes recién llegadas, atendiendo a sus distintos niveles de formación y de conocimientos previos sobre el país; por el aumento de la flexibilidad de dichos programas de acogida, mediante cursos de media jornada y nocturnos, módulos acelerados, cursos a distancia y en línea; por la financiación de programas o modelos de integración innovadores que incluyeran formación lingüística y talleres de comunicación, así como información sobre los aspectos culturales, políticos y sociales del país de acogida (cit. en Villareal, 2009: 14).

Más recientemente, la Comunicación de la Comisión al Parlamento Europeo, al Consejo, al Comité Económico y Social Europeo y al Comité de las Regiones sobre una Política Común de Inmigración, de 2007, volvía a destacar la importancia de los conocimientos de la lengua de la sociedad de acogida, calificándolos de cruciales para la integración, y señalando que las personas emigrantes pueden verse atrapadas en un círculo vicioso en el que, por una parte, encuentren restringido su acceso al mercado laboral debido a sus escasos conocimientos lingüísticos y, por otra, esto mismo impida el desarrollo de tales conocimien- tos a través del empleo y la formación. En el mundo que vivimos, estar alfabetizado es una necesidad y, sin embargo, no lo viven así todas las personas analfabetas autóctonas, ni todas las personas inmigrantes analfabetas en el idioma del país al que emigran (Elejabeitia, 2006: 13).

De otro lado, el valor de la enseñanza de la lengua materna también se ha constatado desde hace bastantes años. Ya en 1953, un comité de personas expertas de la Unesco que estudiaba cuestiones relacionadas con el idioma y la educación encontró muchas ventajas en la enseñanza en la lengua materna:

Es indiscutible que el mejor medio para enseñar a un niño es su lengua materna. Psicológicamente, su lengua materna es un sistema de signos coherentes que en la mente del niño funcionan automáticamente para comprender y expresarse. Sociológicamente, es el medio de identificación entre los miembros de la comunidad a la que pertenece. Pedagógicamente, aprende más rápido que mediante el uso de un medio lingüístico que no le es familiar (Unesco, 1953: 11).

Unicef también ha mostrado su coincidencia con las posturas defendidas por la Unesco a este respecto:

Hay abundantes investigaciones que indican que los estudiantes aprenden más rápidamente y adquieren más fácilmente otras aptitudes académicas cuando la enseñanza comienza en su lengua materna [...]. Además, estos niños también aprenden un segundo idioma más rápidamente que quienes inicialmente aprendieron a leer en un idioma no familiar (Unicef, 1999: 41).

Estos postulados fueron reiterados por la Unesco en 2003, fecha de la publicación de La educación en un mundo plurilingüe, obra en la que se declara que virtualmente todas las investigaciones efectuadas desde 1953 han servido para confirmar los argumentos anteriores en apoyo de programas educativos en la lengua materna.

En esta misma línea, Cummins (cit. en Jiménez Gámez, 2012: 148-149) ha realizado diversas investigaciones en todo el mundo refiriéndose casi siempre a la enseñanza del inglés como segunda lengua, y ha llegado a una serie de conclusiones aplicables al conocimiento de las dos lenguas oficiales de la Comunidad Autónoma del País Vasco:

- Las competencias lingüísticas que se adquieren en la primera lengua no tienen que ser un estorbo para el aprendizaje de la segunda; es más, cuanto mejor domine una persona su propia lengua, más posibilidades tiene de poseer un buen dominio del segundo idioma.

- Es fundamental la consideración positiva del profesorado sobre la lengua materna de su alumnado inmigrante, de modo que éste se sienta reconocido. 
- Es recomendable contar con docentes que procedan de las culturas minoritarias, sobre todo si hay alguna mayoritaria que predomina entre ellas. Hay que tener en cuenta que algunas lenguas maternas son ágrafas (como el árabe dialectal que hablan las personas inmigrantes marroquíes) y, por tanto, no están normativizadas y no se pueden utilizar como lenguas de enseñanza-aprendizaje

Numerosas investigaciones defienden que, en contextos multilingüísticos y multiculturales, es erróneo pensar que las personas inmigrantes tienen que olvidar su lengua materna para aprender una segunda lengua, la de la sociedad de recepción. El aprendizaje y afianzamiento del idioma materno es, en cambio, fundamental en el desarrollo lingüístico, social y cognitivo, y no hace sino favorecer la adquisición de un segundo idioma, por lo que resulta de gran importancia reforzar su aprendizaje.

Desde la administración pública vasca, en esta línea, se ofrecen clases de español y de euskera, siendo principalmente las primeras las que, al igual que en el resto del Estado español, cuentan cada vez con mayor aceptación entre la población marroquí (Relaño y Soriano, 2006: 88). Estas clases de idioma son generalmente impartidas por los centros de educación permanente de personas adultas, por los euskaltegis ${ }^{2}$ o por algún programa específico de los servicios sociales o de educación.

En todo caso, la población magrebí mayor de 16 años es la que muestra un mayor desconocimiento del español (un $4 \%$, frente al $1 \%$ de la población inmigrante mayor de 16 años afincada en Euskadi). Ahora bien, el desconocimiento de este idioma entre las mujeres magrebíes es claramente superior (abarca al $10 \%$ de este colectivo femenino). Por su parte, el euskera no supone hoy día, ni mucho menos, una alternativa para la comunicación entre la población autóctona e inmigrante residente en esta comunidad autónoma. Este idioma es desconocido para el $67 \%$ de la población de origen extranjero mayor de 16 años, y apenas un $4 \%$ de la población magrebí señala tener un nivel de competencia en esta lengua bueno o muy bueno (Gobierno Vasco, 2011: 90). Ocho de cada diez mujeres magrebíes afirman asimismo desconocer el euskera, siendo en muchas ocasiones básico el nivel de conocimiento entre las mujeres restantes (Emakunde, 2012: 109). Los datos muestran, por tanto, que las mujeres del Magreb son las que conforman el colectivo inmigrante con más desconocimiento de las dos lenguas de la sociedad de recepción: el castellano y el euskera. Una situación que justifica en buena medida el aislamiento de una parte significativa de este grupo poblacional con respecto a la sociedad receptora. Es en este contexto y ante esta realidad, donde hay que ubicar las actuaciones llevadas a cabo tanto por organizaciones públicas como adulta. por movimientos populares con el objeto de impulsar e implementar iniciativas y proyectos de promoción del aprendizaje de ambos idiomas entre la población inmigrante, como parte del proceso de normalización lingüística y de integración en el país de acogida.

Entre los distintos proyectos diseñados en la última década para el aprendizaje del euskera por parte de la población inmigrante, podemos destacar, por ejemplo, el programa Aisa, diseñado con la participación de la Viceconsejería de Política Lingüística, $\mathrm{HABE}^{3}$ y la Dirección de Inmigración del Gobierno Vasco, en respuesta a la aplicación del Plan General de Promoción de Uso del Euskera y del Plan Vasco de la Inmigración. Este programa, dirigido a "construir puentes entre diferentes culturas, porque no solamente los/las que vienen de fuera conocen mejor nuestra cultura, sino que la ciudadanía vasca es consciente de que también nosotros/as tenemos que aprender de ellos/as", conforma una experiencia novedosa por la "manera tan distinta en la que deben plantearse las clases si se compara con otros cursos de euskaldunización. [...] Desde HABE se estima que, con estos cursos de euskera, se abre un mundo nuevo para quienes participan en los mismos, aunque sólo sea para reconocer por las calles los rótulos o el contenido de algunos carteles, además de ese acercamiento a la cultura vasca. Es un paso más hacia su integración” (Gobierno Vasco, 2006: 14).

El apoyo al aprendizaje de las lenguas de origen es, por otra parte, mucho más limitado. Al mismo tiempo que es preciso impulsar el conocimiento de los valores culturales y de los idiomas de la sociedad receptora, la creación de una verdadera sociedad intercultural en la que sea posible el desarrollo de las diversas identidades en pie de igualdad exige proporcionar los medios necesarios para conservar y respetar las lenguas de origen y el ambiente lingüístico y cultural de la comunidad inmigrante, fomentando la relación, la colaboración activa y el intercambio de valores culturales entre las distintas partes, sin imposición de ninguna de ellas.

La idea de que la integración no ha de suponer la asimilación, esto es, un proceso unilateral en el que la población inmigrante pierda su lengua y cultura de origen para adoptar únicamente las de la sociedad de destino constituye una reivindicación que, al menos en el plano teórico, ha calado en la comunidad educativa (Vicente Torrado, 2008: 207). En todo caso, las mayores oportunidades para aprender árabe -o la lengua bereber- tanto dentro como fuera de los centros educativos vascos siguen siendo una de las principales reivindicaciones de las mujeres magrebíes, quienes reclaman una mayor implicación de las instituciones públicas vascas en la enseñanza de su idioma materno, tanto para ellas como para sus descendientes (Elejabeitia, 2006: 13; Fuentes

3 Siglas de Helduen Alfabetatze eta Berreuskalduntzerako Erakundea (Organización para la Alfabetización y la Reeuskaldunización de Adultos), entidad dependiente de la Consejería de Educación, Política Lingüística y Cultura del Gobierno Vasco. 
Nogales y Vicente Torrado, 2007: 177-188). La enseñanza del árabe es una de las principales actividades de las asociaciones de mujeres árabe-musulmanas, en un intento de alfabetizar a estas mujeres en su lengua materna. Con ello, no sólo tratan de contribuir al mantenimiento de la identidad cultural de sus asociadas, sino que, además, en el caso de las personas que no saben leer ni escribir en su propio idioma, constituye un paso previo importante en el aprendizaje de otra lengua, como el castellano. Este tipo de formación es, por tanto, clave para el empoderamiento de las mujeres y para su integración en el País Vasco, ya que el analfabetismo en los idiomas de los lugares de origen o de destino condiciona en buena medida la autonomía de las mujeres y su participación como ciudadanas de pleno derecho en la sociedad (Unzueta y Vicente Torrado, 2011: 87-88). Durante todas las fases de la creación de estos programas es vital, además, contar con la participación de las personas integrantes de las comunidades donde se habla la lengua minoritaria, ya que, sin su contribución, implementar esos programas sería extremadamente difícil.

Hasta aquí hemos recabado la visión de las propias mujeres magrebíes. Pero, por otra parte, resulta relevante recabar la de la población vasca acerca de la necesidad de fomentar, desde las instituciones públicas, espacios gratuitos de aprendizaje tanto de las dos lenguas oficiales como de las lenguas maternas de la población inmigrante. En este sentido, cabe destacar que poco más de un tercio de la población autóctona cree que todas las personas inmigrantes de origen extranjero deberían tener acceso gratuito a clases de euskera (35\%) o castellano ( $37 \%$ ), mientras que aproximadamente la mitad limitaría esa posibilidad a la población inmigrante regularizada (49,7\% en el caso de ambas lenguas). Menor es la importancia otorgada, en cambio, al aprendizaje de las lenguas maternas de la población inmigrante. Así, únicamente un $23 \%$ de la población vasca cree que todas las personas extranjeras deberían tener derecho a clases de su lengua materna, mientras que otro $38 \%$ lo restringiría a la población regularizada, al tiempo que casi un tercio de las personas encuestadas (33\%) defiende que ninguna persona inmigrante debería disfrutar de este derecho (Ikuspegi@k-Observatorio Vasco de Inmigración, 2013: 61).

En este apartado, centrado en la dimensión cognitivo-cultural, se ha revelado la importancia del conocimiento de los idiomas, tanto de la sociedad de acogida como de la origen, en la integración de las mujeres de origen magrebí. Una tarea todavía pendiente, dado el limitado conocimiento del castellano y el prácticamente inexistente conocimiento del euskera por parte de este colectivo. El mayor esfuerzo para lograr este objetivo tendrá que ser realizado, sin duda, por parte de la población femenina de origen magrebí. Ahora bien, hay que recordar que la integración social en clave intercultural constituye un proceso bidireccional, en el que la sociedad y las instituciones de acogida también han de jugar un papel relevante, que, en esta dimensión, no ha de limitarse a la oferta de clases que favorezcan el aprendizaje del euskera y del castellano, sino que además ha de promover el respeto y el aprendizaje de las lenguas de origen, opinión no muy compartida por la población vasca, según los datos expuestos anteriormente.

\subsection{Dimensión social}

En este apartado, vamos a abordar en qué medida las mujeres del Magreb se encuentran integradas en la sociedad vasca, teniendo en cuenta algunas variables vinculadas a la dimensión social. Tajfel (1984) definió la identidad social como "aquella parte del autoconcepto de un individuo que deriva del conocimiento de su pertenencia a un grupo (o grupos) social junto con el significado valorativo y emocional asociado a dicha pertenencia" (cit. en Relaño y Soriano, 2006: 89). Para ello, analizaremos algunas dimensiones de la vivencia del islam en la sociedad vasca por parte de la población femenina de origen magrebí.

En el Magreb, existe una mezcla entre lo cultural, lo político, lo social, las tradiciones y lo religioso, y el islam suele abarcar toda ella. En el mundo musulmán, la religión aparece muchas veces como un elemento transversal, utilizado para explicar, justificar, inferir, transformar, limitar, dotar de contenido o de forma aspectos culturales, sociales o políticos. Es decir, que la senda que ha de seguir la población musulmana está trazada tanto para el espacio privado como el público. En el mundo musulmán, la religión y el Estado han estado tradicionalmente unidos.

Esta importante presencia del islam en diferentes espacios de la vida cotidiana es también sentida por las personas musulmanas inmigradas, y va a constituir un elemento clave para interpretar su vida y las formas de concebirla en la sociedad vasca, aunque en este nuevo contexto hayan pasado de vivir en un entorno donde esa religión es mayoritariamente compartida y está presente en casi todas las esferas de la vida a otro donde es muy minoritaria y no siempre está bien vista por parte del resto de la población. Teniendo esto en cuenta, a continuación vamos a analizar dos de los aspectos más controvertidos en la actualidad de la vivencia del islam en Euskadi, como son el uso del velo islámico y la asistencia a las mezquitas, para concluir este apartado con una aproximación a los sentimientos identitarios de pertenencia de estas mujeres magrebíes residentes en la Comunidad Autónoma del País Vasco.

\subsubsection{El uso del hijab}

Hoy día, la mayoría de los hombres magrebíes no visten ropa tradicional, ni siquiera en los países de origen, lo que hace que no experimenten importantes cambios en su vestimenta con motivo de la emigración. Entre las mujeres magrebíes, en cambio, es común el uso del velo islámico, atuendo que 
está abriendo importantes debates en el entorno de recepción (Benítez Eyzaguirre, 2012; Fuentes Nogales y Vicente Torrado, 2007).

Es preciso dejar claro que normalmente nos referimos al velo islámico para hablar de diferentes atuendos empleados para cubrir el cuerpo. En este sentido, debemos comenzar señalando que la mayoría de las mujeres magrebíes que en la actualidad visten el velo islámico emplean el hijab (nombre que recibe el pañuelo de diferentes colores que cubre el cabello, las orejas y el cuello, dejando la cara al descubierto). Menos frecuente es ya el uso del haik o hayek (capa, generalmente de color beige o blanco, sin ninguna costura, que solían llevar las mujeres magrebíes y que aún llevan algunas mujeres argelinas). Algunas mujeres del Sáhara Occidental, de Mauritania y del sur de Argelia cubren su cuerpo también con un pañuelo de algodón fino y vistosos colores llamado melfa, cuya calidad depende de la actividad para la cual sea elegido. Estas vestimentas difieren bastante de otros tipos de velo, como son el niqab (velo negro que cubre todo el cuerpo e incluso la cara, dejando únicamente los ojos al descubierto, utilizado principalmente por las mujeres musulmanas suníes de Oriente Medio y, últimamente también, de Egipto) o el burka, impuesto a las mujeres por el régimen talibán afgano (túnica que, como el niqab, cubre todo el cuerpo, la cabeza, la cara e, incluso, parte de los ojos, ya que apenas deja una abertura rejada a su altura, con los problemas de visión que ello conlleva para las mujeres que lo visten). Estos últimos tipos de velo son los que provocan mayores rechazos, tanto en las propias sociedades de origen como, sobre todo, en los países de recepción (Fuentes Nogales y Vicente Torrado, 2007: 115).

Con el uso del hijab y de ropas amplias que no marquen excesivamente las formas corporales, muchas mujeres musulmanas tratan de cumplir con la obligación recogida en el Corán de cubrir el cuerpo, sobre todo en la edad adulta, con el objeto de no llamar la atención y no atraer las miradas masculinas. Según los preceptos coránicos, las mujeres deben, además, evitar la coquetería y no tratarán de seducir a los hombres con voz, palabras ni comportamientos provocadores. De esta forma, se verán protegidas de hombres malintencionados que no las dispensen el debido trato. Tanto los varones como las mujeres, por otra parte, deberán bajar la vista con recato, y ser castos y correctos. La fe y el pudor están entrelazados, por lo que el cumplimiento de estos preceptos implica un mayor acercamiento a Dios, quien evaluará en su momento estos comportamientos.

Fátima Mernissi (cit. en El Hadri, 2009: 64), socióloga marroquí, se refiere al hijab de la siguiente manera:

El concepto de hijab es tridimensional y las tres dimensiones coinciden muy a menudo. La primera es visual: sustraer a la mirada. La raíz del verbo hayaba quiere decir 'esconder'. La segunda es espacial: separar, marcar una frontera, establecer un umbral. Y, por último, la tercera es ética: incumbe el dominio de lo prohibido. A ese nivel, no se trata ya de categorías palpables, que existen en la realidad de los sentidos, como lo visual o lo espacial, sino de una realidad abstracta, del orden de las ideas. Un espacio oculto por un hijab es un espacio prohibido.

La principal motivación de las mujeres magrebíes para llevar el hijab es religiosa: está relacionada con la vivencia de la religión musulmana, con la identificación y reconocimiento como miembros de la comunidad islámica y con la necesidad de cumplir con esta obligación coránica. En este sentido, se destaca también que, si es un pecado no llevar el hijab, más lo es aun quitárselo después de haberlo llevado (Etxeberria, Ruiz Vieytez y Vicente Torrado, 2007: 141-142). No obstante, también son aducidas otras razones para su uso: algunas mujeres también destacan la necesidad de llevar el velo en la esfera pública con el objeto de pasar inadvertidas o de no llamar la atención, ni ser valoradas únicamente por su apariencia física. Y tampoco faltan mujeres que manifiestan su voluntariedad a la hora decidir llevar el hijab, sin ser coaccionadas por presiones familiares, religiosas o sociales, estando su opción más vinculada a un signo de identidad cultural o de reivindicación feminista que a una obligación religiosa.

Ahora bien, tampoco faltan opiniones que defienden que son muy pocas las mujeres que se ponen el pañuelo por propio deseo, mientras que la mayoría lo hace como una respuesta a la presión social. Y ello aun cuando su efecto sea muy inferior en la sociedad de recepción respecto de la sociedad de origen (Lacomba, 2001: 213). Las mujeres con pañuelo son tratadas de manera más respetuosa por los hombres árabes que las que no lo llevan, siendo este control social muy importante a la hora de decidir si vestirlo o no. Algunos miembros masculinos de la familia -especialmente maridos, padres o hermanos mayores- se consideran con derecho a obligar a sus esposas, hijas o hermanas a llevar el pañuelo, con independencia de su voluntad y con el objetivo de mantener la estabilidad familiar y social, lo que ha llevado a que esta prenda sea calificada precisamente como un símbolo de la dominación del hombre sobre la mujer. Pero dicho esto, conviene recordar que tampoco faltan quienes defienden que el velo, en cualquiera de sus formas, no es la expresión de la sumisión de las mujeres a los varones o de su marginación social, sino todo lo contrario: es lo que libra a las mujeres de ser tratadas como objetos, únicamente valoradas por su belleza física.

Hay mujeres que se ven forzadas a llevar el hijab por el control social ejercido por su propia comunidad. Pero no es menos cierto que la sociedad vasca también llega a ejercer cierto control sobre ellas, aunque en el sentido contrario. Así, algunas mujeres magrebíes afirman sentirse menos aceptadas socialmente, e incluso discriminadas, precisamente por el hecho de llevar el velo, situación que ha empujado incluso a algunas de ellas a dejar de utilizarlo con el objeto de lograr una mayor aceptación social y de no limitar, 
por ejemplo, sus opciones de encontrar un trabajo remunerado. En otros casos, se ha optado por renunciar a su uso tan sólo en algunos ámbitos, como el laboral, mientras que se continúa utilizando en otros. En todo caso, estas situaciones también ponen de manifiesto cómo la libertad de estas mujeres queda coaccionada, aun con el pretexto de defender su identidad propia y su mayor capacidad de decisión personal.

En definitiva, el asunto de la vestimenta de las mujeres magrebíes sigue siendo tremendamente controvertido. Aun así, poner el énfasis únicamente en el uso o no uso hijab por parte de estas mujeres no soluciona el problema, sino que sería necesario llevar a cabo también una intervención sociopolítica y educativa más profunda, que abarque tanto a la comunidad musulmana como a la sociedad receptora, con el objeto de favorecer el desarrollo de un espíritu crítico que nos permita analizar la realidad a ambas partes, garantizando el respeto de todos los derechos humanos de estas mujeres.

\subsubsection{Las mezquitas}

La red familiar o la red de amistades y de personas conocidas suele convertirse frecuentemente en un puente entre la sociedad de origen y la sociedad receptora para las mujeres magrebíes recién llegadas. Cuando esto ocurre, el choque cultural que se produce en el proceso migratorio parece reducirse considerablemente, pero la integración en la sociedad de acogida también suele ser más lenta, debido a que se tiende a mantener un fuerte contacto con la gente del propio país. Quienes llegan sin contar con una red de apoyo suelen relacionarse, en cambio, más rápidamente y con más frecuencia con personas de la sociedad receptora, y los contactos que mantienen con su grupo territorial, religioso o étnico tienden a ser más personales y no tan colectivos.

La mezquita, lugar de culto o casa de oración de la comunidad musulmana, se convierte también en un lugar de socialización en la sociedad de recepción entre las personas procedentes del Magreb. Las mezquitas, como las asociaciones u otros lugares de encuentro de la población magrebí, realizan funciones culturales y sociales, ofreciendo, por ejemplo, un acompañamiento que resulta de gran importancia para las personas que no disponen de una red familiar de apoyo (Etxeberria, Ruiz Vieytez y Vicente Torrado, 2007).

La mezquita conforma el principal lugar de encuentro en el que se desarrolla el sentimiento de pertenencia e identidad de la comunidad musulmana. Ahora bien, nuevamente encontramos importantes diferencias de género a la hora de evaluar la asistencia a estos centros de culto de hombres y mujeres. Muchos musulmanes acuden a diario, aunque el encuentro más importante y numeroso es el que tiene lugar los viernes. La mayoría de las mujeres, en cambio, asegura que no acuden nunca o casi nunca a la mezquita, siendo dos las principales razones de ello. En primer lugar, según la religión musulmana, los hombres están obligados a acudir a la mezquita los viernes, mientras que para las mujeres la asistencia es opcional. En segundo lugar, el espacio de las mezquitas en sus lugares de origen está dividido de forma que mujeres y hombres no se ven. En Euskadi, en cambio, son todavía muy pocos los lugares de oración habilitados para el encuentro de la comunidad musulmana y, además, son salas de un tamaño tan reducido que no es posible su división en un espacio para hombres y otro para mujeres. Todo ello se traduce en la falta de lugares para el encuentro de la comunidad musulmana femenina, situación que tampoco se ve favorecida por las normativas establecidas recientemente para la apertura de centros de culto (Ayuntamiento de Bilbao, 2013).

Dada la presencia mayoritariamente masculina de la inmigración magrebí (aunque cada vez sea mayor el número de mujeres de esta procedencia en nuestra sociedad), las dificultades para conseguir un local apropiado para abrir una mezquita y la prioridad que la oración colectiva tiene para los hombres musulmanes, la mayoría de las mezquitas constituyen lugares para el encuentro de los hombres, mientras que las mujeres quedan fuera de todo este elenco de relaciones y ventajas sociales que se tejen alrededor de ellas. Con el paso del tiempo, algunas mezquitas han logrado disponer de un lugar separado para la oración de las mujeres, aunque estos espacios no suelen ser lo suficientemente amplios como para permitir el encuentro femenino con motivo de ciertas fiestas o celebraciones. Es por ello por lo que ésta se convierte en una de sus principales reivindicaciones, dirigida no únicamente hacia su propia comunidad, sino también hacia las instituciones públicas (Fuentes Nogales y Vicente Torrado, 2007; Etxeberria, Ruiz Vieytez y Vicente Torrado, 2007).

En definitiva, los usos de las mujeres musulmanas en nuestra sociedad están encuentran frecuentemente sometidos a debate, y ellas se encuentran en medio de esta encrucijada: en la medida en que mantengan los usos y costumbres de su sociedad de origen, se encontrarán más aceptadas por los miembros de su comunidad; y en la medida en que se alejen de aquéllos, sentirán una mayor presión social y un mayor aislamiento por parte de la comunidad. En cambio, en la sociedad de acogida, ocurrirá lo contrario. Es preciso, por tanto, superar esta disyuntiva si realmente se quiere trabajar por la integración social de este colectivo femenino.

\subsection{Dimensión de identidad}

En este apartado, vamos a analizar la percepción subjetiva de pertenencia a la sociedad de acogida de las mujeres del Magreb y la actitud de la población vasca hacia ellas. Integración e identidad son dos conceptos que a menudo van unidos cuando hablamos de inmigración. Aparecen a veces como elementos inseparables y a veces como irreconcilia- 
bles. La idea de fondo que en la actualidad generalmente se baraja al teorizar sobre estos temas es que las personas extranjeras sean miembros integrados en la sociedad receptora y que participen en ella sin perder su propia identidad, sin que tengan que verse obligadas a cambiar su identidad.

Pero la identidad y la cultura de las personas -autóctonas o inmigrantes- no son estancas ni estáticas, sino que están en constante transformación y caminan en paralelo, puesto que se adquieren a través del aprendizaje continuado. De esta forma, todas las personas vamos construyendo una identidad cultural múltiple, en función de los grupos con los que nos relacionamos. La yuxtaposición de identidades culturales diversas en un mismo espacio político ha provocado la destrucción de las identidades tradicionales y la normalización de las identidades mestizas. Cualquier supuesta identidad es una construcción dinámica, hecha de préstamos, intercambios y mestizajes (Maalouf, 2001; Jiménez Gámez, 2012: 145-146). La identidad y los códigos culturales se van adquiriendo a lo largo de la vida, y dentro de cada comunidad pueden ser compartidos diferencialmente, puesto que no todos sus miembros viven la cultura y la identidad de la misma manera. Más aún, en el interior de las comunidades pueden generarse subculturas, lo cual se explica por factores como el género, el grupo de edad, la clase social o el medio procedencia (rural o urbano).

En este sentido, entre las mujeres de origen magrebí residentes en Euskadi encontramos dos modelos de autoidentificación principales, uno correspondiente a una identidad religiosa, y el otro a una identidad nacional, aunque en realidad los dos modelos se entremezclan (Fuentes Nogales y Vicente Torrado, 2007: 162).

En general, la población inmigrante extranjera se siente mucho más identificada con la nacionalidad de origen que con el sentimiento identitario español o vasco, y lo mismo ocurre con las mujeres inmigrantes internacionales. Concretamente, las mujeres marroquíes se ubican en la puntuación de 4,5 en una escala de 1 ('nada') a 5 ('mucho') en su sentimiento identitario de origen, frente al 2,3 de su sentimiento identitario vasco y al 2,1 de su sentimiento identitario español (Emakunde, 2012: 141-142).

En cuanto a las prácticas culturales del país de origen y de acogida, las mujeres marroquíes conforman uno de los colectivos de inmigrantes femeninos con menores signos de mestizaje. Estas mujeres son las que en su vida cotidiana más mantienen, en cambio, las costumbres de su país y las que menos siguen las costumbres vascas. Quizá por ello, no sorprende que sean el grupo de mujeres inmigrantes que menos amistades con personas vascas o españolas dicen tener, y que menos relaciones de ocio mantienen con la población autóctona, mientras que las amistades de su país y de otros países se mueven en unas puntuaciones muy similares a las del resto de principales nacionalidades extranjeras presentes en Euskadi (Emakunde, 2012: 145).
Pero las menores relaciones sociales mantenidas entre la población de origen magrebí y la autóctona no se deben sólo a la actitud del primer grupo. Según el barómetro lkuspegi@k (2013: 69), los colectivos del Magreb son los que menor simpatía despiertan entre la sociedad vasca, siendo muy reducidos - los más bajos- tanto el interés como los esfuerzos de integración que la sociedad vasca les atribuye.

La población inmigrante percibida como más cercana desde el punto de vista cultural, político o social es vista con mayor simpatía, y a ella se le adjudica, a su vez, un mayor esfuerzo de integración, con lo que este proceso de alguna manera se retroalimenta y se refuerza. La población autóctona vincula el grado de integración con el grado de simpatía que siente por las distintas nacionalidades u orígenes, por lo que aquellos colectivos considerados más lejanos cultural o socialmente serán los destinatarios de un mayor número de prejuicios y estereotipos (Ikuspegi@kObservatorio Vasco de Inmigración, 2013: 69). Por ello no sorprende que las mujeres del Magreb sean percibidas como uno de los colectivos inmigrantes femeninos con mayores dificultades de integración en Euskadi (Emakunde, 2012: 153).

En la sociedad de acogida, la imagen de la inmigración musulmana se encuentra inseparablemente unida a la percepción general del islam. Se ha construido un discurso paradigmático donde la diferencia en torno a las mujeres magrebíes es comprendida como problemática (Benítez Eyzaguirre, 2012: 94). Y por otra parte, la imagen creada por Occidente en torno al mundo árabe ha generado en la población del Magreb una reacción dirigida al mantenimiento de su identidad y a la defensa de su cultura (Lacomba, 2001: 124). El islam pasa a convertirse así en un importante factor de regulación social en el nuevo contexto, al mismo tiempo que da lugar a cierto repliegue comunitario.

Los prejuicios construidos por la sociedad de acogida pueden tener grandes repercusiones sobre la actitud de las personas inmigrantes, al sentirse infravaloradas. Así, frente a una situación de mantenimiento de estereotipos, en combinación con una situación de exclusión social continuada, una de las reacciones posibles puede ser el reforzamiento y la exteriorización de la identidad propia, construida sobre la pertenencia de base religiosa (Lacomba, 2001: 125).

La población inmigrante del Magreb se siente juzgada por la sociedad de acogida, poniéndose de manifiesto la influencia ejercida por los medios de comunicación en este sentido. El tratamiento parcial de las informaciones sobre el mundo musulmán los convierte en productores y mantenedores de los extendidos prejuicios (Lacomba, 2001: 125). Las ideas preconcebidas, surgidas de la ignorancia y del miedo a lo ajeno, son recogidas por los medios de comunicación, que transmiten una imagen de peligro, enemistad, problema y, especialmente, de las mujeres como víctimas. Representadas como víctimas de la ignorancia (analfabetas), de los hom- 
bres (dependientes) y de la religión (sumisas), las mujeres magrebíes son vistas desde Occidente como pasivas sufridoras y cómplices de una segregación social y familiar frente a la que deberían rebelarse (Sande, 2007: 29). Estas mujeres sufrirían, en conecuencia, una múltiple discriminación, en tanto que mujeres, inmigrantes y musulmanas.

En síntesis, las mujeres inmigrantes del Magreb mantienen un sentimiento identitario más vinculado a sus países de origen que a la sociedad de acogida, debido, al menos en parte, a que muchas de ellas llevan todavía poco tiempo en nuestra sociedad. Estas mujeres presentan todavía con demasiada frecuencia un escaso conocimiento de alguna de las lenguas oficiales en Euskadi, esto es, del euskera o del castellano, lo que seguramente explica, en buena medida, sus más reducidos vínculos con la población vasca en sus relaciones sociales y en la vivencia del ocio, así como el mayor mantenimiento, en cambio, de relaciones endogámicas con personas de su misma comunidad de origen.

Ahora bien, tampoco debemos olvidar que esta situación puede ser, asimismo, alimentada por la propia actitud de distanciamiento que, hacia este colectivo, muestra la población autóctona, y que se ve favorecida desde los medios de comunicación. La actitud de rechazo y los prejuicios que la sociedad receptora comparte hacia las mujeres del Magreb son percibidas por éstas y provocan en muchas ocasiones la reacción contraria a la deseada por la sociedad vasca. Tal como hemos comentado, las personas tienden a mantenerse vinculadas a su comunidad para protegerse frente al rechazo que sufren por parte de la sociedad de recepción, por lo que también será necesario reflexionar sobre la actitud de la sociedad vasca para no seguir alimentando la segregación de las mujeres musulmanas en nuestra sociedad, un efecto contrario al deseado.

\section{Conclusiones}

La sociedad vasca ha optado por gestionar la integración social a través de un modelo intercultural, por lo que entiende que es éste un proceso bidireccional, en el que han de tomar parte activa tanto las mujeres inmigrantes llegadas del Magreb como todas las personas de la sociedad de acogida. Los resultados del análisis de las distintas dimensiones consideradas nos indican que, en todos los aspectos considerados, queda un importante camino por recorrer en la integración de estas mujeres de origen magrebí. En cualquier caso, no debemos olvidar que la responsabilidad de dicha integración no recae únicamente sobre ellas o sobre sus comunidades de origen, sino que también es compartida por la sociedad de recepción y sus instituciones, que habrán de tomar asimismo las medidas adecuadas para favorecer su incorporación en condiciones de igualdad. El mayor esfuerzo en dicho proceso lo tendrán que hacer las personas que están llegando hasta la sociedad vasca para establecerse en ella, pero la sociedad de acogida tiene que serlo realmente, eliminando los obstáculos al disfrute de los derechos humanos, entre los que se incluyen los derechos civiles, políticos, económicos, sociales y culturales. Esta perspectiva es también la que debe guiar los programas y las actuaciones llevadas a cabo desde el trabajo social, unas intervenciones que, alejadas de lecturas etnocéntricas y únicamente basadas en las diferencias culturales, consideren las distintas dimensiones de la integración, evaluando asimismo los resultados de dichas intervenciones.

El análisis de la situación objetiva de las mujeres magrebíes y el trabajo junto a ellas nos ayudará a conocer y comprender en mayor medida la realidad de este colectivo y su cultura, así como a mejorar sus condiciones de vida y la convivencia entre los distintos grupos socioculturales que conforman nuestra sociedad. Este diagnóstico objetivo nos permitirá cambiar el foco de atención a la hora de abordar un plan individual de atención con las mujeres del Magreb, ampliando nuestro horizonte y teniendo en cuenta más variables que la simple diferencia cultural. Y ello porque el centro del problema no está en la existencia de distintas culturas que conviven en un mismo espacio social, sino en el modo en que se gestiona la diversidad con el objeto de lograr una convivencia intercultural, en la que todas las personas participemos y nos enriquezcamos:

Debemos mirar más allá del velo. Pero no de aquel que ellas visten, sino del que los prejuicios y el desconocimiento tejen ante nuestros ojos y nos impide ver por encima de las diferencias culturales (Sande, 2007: 30). 
AYUNTAMIENTO DE BILBAO (2013): “Acta de la sesión ordinaria celebrada por el Excmo. Ayuntamiento. Pleno el día 25 de septiembre de 2013”, págs. 16-36 ['http://is.gd/RRfON4>].

BENÍTEZ EYZAGUIRRE, L. (2012): “Las mujeres marroquíes en los medios de comunicación”, Perspectivas de la Comunicación, vol. 5, nº 1, págs. 91-102.

BLANCO FERNÁNDEZ VALDERRAMA, C. (2002): “LOS inmigrantes y su integración. Apuntes en torno a una creciente nebulosa de conceptos, modelos y políticas", en GARCÍA CASTAÑO, F. J.; y MURIEL LÓPEZ, C. (ed.), La inmigración en España: contextos y alternativas, Granada, Universidad de Granada, págs. 71-81.

- (2001): "La integración de los inmigrantes. Fundamentos para abordar una política global de intervención”,

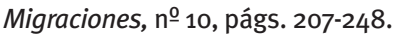

- (1993): La integración de los inmigrantes en las sociedades receptoras: método de análisis y aplicación al País Vasco [tesis doctoral inédita], Universidad de Deusto.

CEBRIÁN, I.; y MORENO, G. (2008): Cómo abordar la integración de las mujeres inmigrantes. Guía para las administraciones públicas, Madrid, Instituto de la Mujer.

CHECA, F.; ARJONA, A.; y CHECA, J. C. (2003): La integración social de los inmigrados: modelos y experiencias, Barcelona, Icaria.

COMISIÓN EUROPEA (2007): Comunicación de la Comisión al Parlamento Europeo, al Consejo, al Comité Económico y Social Europeo y al Comité de las Regiones. Una política común de inmigración, COM (2007) 780 final, pág. 10 [rhttp://eur[<http://eur-lex.europa.eu/legal-content/ ES/NOT/?uri=CELEX:52007DC0780\&q id $=1410197173062\rangle]$.
EMAKUNDE (2012): Mujeres inmigrantes extranjeras en la $C A E$, Vitoria-Gasteiz, Emakunde.

ELEJABEITIA, C. (2006): Mujeres inmigrantes en la educación de las personas adultas, Madrid, Instituto de la Mujer.

EL HADRI, S. (2009): Los derechos de la mujer en el islam y su estatuto personal en el Magreb (Marruecos, Argelia y Túnez), Valencia, Ceimigra.

ETXEBERRIA, X.; RUIZ VIEYTEZ, E.; y VICENTE TORRADO, T. L. (2007): Identidad islámica y espacio público en el País Vasco, serie Derechos Humanos, Alberdania.

FUENTES NOGALES, J. L.; y VICENTE TORRADO, T. L. (2007): La población magrebí en el País Vasco, VitoriaGasteiz, Ararteko.

GIMÉNEZ ROMERO, C. (2003): Qué es la inmigración, Barcelona, RBA.

GOBIERNO VASCO. DEPARTAMENTO DE EMPLEO Y ASUNTOS SOCIALES (2011): Encuesta de la población inmigrante extranjera residente en la Comunidad Autónoma del País Vasco. EPIE, 2010, Gobierno Vasco [〈https://euskadi.net〉]

GOBIERNO VASCO. SECRETARÍA GENERAL DE ACCIÓN EXTERIOR (2006): "Aisa: un paso más hacia la integración”, Euskal Etxeak, noำ12, pág.14.

IKUSPEGI@K-OBSERVATORIO VASCO DE INMIGRACIÓN (2013): Barómetro 2013. Percepciones y actitudes hacia la inmigración extranjera, Bilbao, Ikuspegi@k [<http://www. ikuspegi-inmigracion.net/documentos/ barometros/2013/bar_2013_casOK.pdf〉]

- (2012): “Mujer inmigrante en la CAPV”, Panorámica de la inmigración, n- 47. 
INE (2014): Estadísticas del Padrón Continuo, Madrid, Instituto Nacional De Estadística [<https:// www.ine.es>].

JIMÉNEZ GÁMEZ, M. A. (2012): “Diversidad cultural y lingüística, identidad e inmigración: algunas conclusiones y propuestas desde la investigación educativa", Revista Educación Inclusiva, vol. 5, no-1, págs. 139-156.

KYMLICKA, W. (1996): Ciudadanía multicultural, Barcelona, Paidós.

LACOMBA, J. (2001): El islam inmigrado. Transformaciones y adaptaciones de las prácticas culturales y religiosas, Madrid, Ministerio de Educación, Cultura y Deporte.

LUCAS, J. DE; y TORRES, F. (eds.) (2002): Inmigrantes: ¿cómo los tenemos? Algunos desafíos y (malas) respuestas, Madrid, Talasa.

MAALOUF, A. (2001): Identidades asesinas, Madrid, Alianza.

MALGESINI, G.; y GIMÉNEZ, C. (1997): Guía de conceptos sobre migraciones, racismo e interculturalidad, Madrid, La Cueva del Oso.

MARTÍN, M. J.; MORENO, G.; y FULLAONDO, A. (2012): Mujer inmigrante en la CAPV 2010, Bilbao, Ikuspegi@k-Observatorio Vasco de Inmigración.

NIESSEN, J.; y SCHIBEL, Y. (2004): Manual sobre la integración para responsables de la formulación de políticas y profesionales, Bruselas, Comisión Europea [rhttp://ec.europa. eu/spain/pdf/integracion_inmigrantes_ es.pdf〉].

PUMARES, P. (1998): “¿Qué es la integración? Reflexiones sobre el concepto de integración de los inmigrantes", en CHECA Y OLMOS, F. (ed.), Africanos en la otra orilla, Barcelona, Icaria, serie Antrazyt, págs. 289-318.

RELAÑO, A. M.; y SORIANO, R. M. (2006): “La vivencia del idioma en mujeres migrantes. Mexicanas en Estados Unidos y marroquíes en España", Migraciones Internacionales, vol. 3, nํㅜ 4, págs. 85-117 [<http://www.redalyc.org/articulo. oa?id=15130404>].
RETORTILLO, A. et al. (2008): “Inmigración y modelos de integración: entre la asimilación y el multiculturalismo", Ruct, n- 7, págs.124-138 [〈www.ruct.uva.es/pdf/Revista\%207/7106〉].

ROCHER, G. (1985): Introducción a la sociología general, Barcelona, Herder.

SANDE, M. (2007): El Magreb con ojos de mujer, Madrid, Solidaridad Internacional.

SANTAMARÍA, E. (2002): La incógnita del extraño. Una aproximación a la significación sociológica de la 'inmigración no comunitaria', Barcelona, Anthropos.

TAYLOR, C. (2001): El multiculturalismo y la 'política del reconocimiento', México D. F., Fondo de Cultura Económica.

UNESCO (2003): La educación en un mundo plurilingüe, París, Unesco.

- (1953): Empleo de las lenguas vernáculas en la enseñanza, París, Unesco.

UNICEF (1999): Estado mundial de la infancia 1999, Unicef [rhttp://www.unicef.org/spanish/sowc/ archive/SPANISH/Estado\%20Mundial\%20 de\%20la\%2olnfancia\%201999.pdf〉].

UNZUETA, A.; y VICENTE TORRADO, T. L. (2011). "Asociacionismo de mujeres inmigrantes en el País Vasco: actuaciones y desafíos", Zerbitzuan, no 49, págs. 81-91.

VICENTE TORRADO, T. L. (2008): La escuela vasca ante la realidad de la inmigración: un nuevo desafío, Vitoria-Gasteiz, Gobierno Vasco.

VIDAL FERNÁNDEZ, F.; y MARTÍNEZ MARTÍNEZ, J. (2006): Religión e integración social de los inmigrantes: la prueba del ángel, Madrid, Comillas.

VILLAREAL, F. (2009): Enseñanza de la lengua a inmigrantes. Estudio de políticas de integración lingüística en tres países europeos y retos para el caso español, Madrid, Ministerio de Trabajo e Inmigración. 
